\title{
Toxicity with small molecule and immunotherapy combinations in non-small cell lung cancer
}

\author{
H. Adderley ${ }^{1}$ · F. H. Blackhall ${ }^{1,2,3} \cdot$ C. R. Lindsay ${ }^{1,2,3}$
}

Received: 6 May 2020 / Accepted: 31 August 2020 / Published online: 11 September 2020

(C) The Author(s) 2020

\begin{abstract}
Treatment stratification in stage IV NSCLC is guided by identification of oncogene driver mutations. Actionable mutations with current licenced therapeutic agents include epidermal growth factor receptor (EGFR), rearrangements of anaplastic lymphoma kinase (ALK), ROS-1 and BRAF V600. Alongside progress with small molecule therapy, developments in immune checkpoint inhibitors (CPIs) have transformed the landscape of stage III and stage IV NSCLC. The success of CPIs has led to evaluation with small molecule therapy in both concurrent and sequential settings. In this review we summarise recent results of combination CPIs and tyrosine kinase inhibitors (TKIs) in stage IV NSCLC, detailing significant toxicity and its potential mechanisms with both concurrent and sequential approaches. As more therapeutic targets are being discovered it is becoming increasingly important for clinicians to correctly sequence therapy for delivery of safe and effective treatment. In addition to stage IV disease we suggest that comprehensive molecular profiling of key NSCLC drivers, particularly in stage III disease, will help to inform optimal treatment sequencing and minimise potential toxicity.
\end{abstract}

\section{Introduction}

Molecular aberrations or oncogene driver mutations in non-small cell lung cancer (NSCLC) are frequently used to stratify treatment for patients with stage IV disease. Actionable mutations in the epidermal growth factor receptor $(E G F R)$, rearrangements of anaplastic lymphoma kinase (ALK) ROS- 1 and BRAF V600 represent targets with current licenced therapeutic agents that can improve progression-free survival (PFS) and overall survival (OS) [1, 2]. These include EMA- and FDA-approved erlotinib, gefitinib, afatinib and osimertinib for EGFR-mutant cancers. Alectinib, crizotinib, ceritinib, brigatinib and lorlatinib for ALKrearranged cancers, as well as dabrafenib and trametinib for BRAF V600 mutant disease [3-15]. Other oncogene driver mutations or alterations are the subject of ongoing evaluation in clinical trials, with further standard of care breakthroughs

C. R. Lindsay

colin.lindsay1@nhs.net

1 Department of Medical Oncology, The Christie NHS Foundation Trust, Manchester, UK

2 Division of Molecular and Clinical Cancer Sciences, University of Manchester, Manchester, UK

3 Cancer Research UK Lung Cancer Centre of Excellence, London and Manchester, Manchester, UK expected for small molecules targeting NTRK, RET, HER2/ MET and KRAS G12C subsets in particular. Indeed, the FDA have recently approved selpercatinib for RET and entrectinib for NTRK mutations [16, 17].

In parallel to this progress, recent developments in immune checkpoint inhibitors (CPIs) have transformed the landscape of stage III and IV NSCLC, conferring significant improvements in PFS and OS in the first and second line settings for advanced stage disease (KEYNOTE 024, OAK, KEYNOTE 010, CM017, CM057) [18-22], as well as improvements in PFS and OS when used as consolidation therapy after concurrent chemo-radiotherapy (CCRT) in stage III disease (PACIFIC) [23]. The success of CPIs has led to their investigation in combination with established therapies including chemotherapy, tyrosine kinase inhibitors (TKIs) and radiotherapy, with further advances in KEYNOTE-189, Keynote-407 and IMpower-130 establishing combination chemo-immunotherapy as a first line treatment option in advanced NSCLC lacking EGFR mutation or ALK rearrangement [24-26]. In addition, IMpower-150 demonstrated an overall survival signal benefit in a subgroup of patients with sensitising $E G F R$ mutation with combination chemo-immunotherapy plus bevacizumab vs bevacizumab and chemotherapy alone. Based on these results, atezolizumab, bevacizumab, carboplatin and paclitaxel (ABCP) have been approved by 
the EMA as first-line therapy for stage IV non-squamous NSCLC including those with low or negative programmed death-ligand 1 (PD-L1) expression. This recommendation includes EGFR and ALK positive tumours who have failed previous targeted therapy $[27,28]$.

The past year has seen evaluation of CPIs in combinations with established TKIs for the first time, so far offering some reasons for disappointment. One particular emerging concern has been the development of severe toxicity, both with concurrent and sequential use of CPI/TKIs. Here we detail results of toxicity when CPIs are used concurrently with TKIs, and late CPI toxicity when CPIs and TKIs are used sequentially.

\section{CPIs in combination with TKIs}

To date, there have been a number of phase I and II clinical trials across various molecular subgroups of NSCLC using different CPI/TKI combinations (Table 1). Toxicity concerns were identified in the TATTON trial [29] evaluating the combination of osimertinib, an EGFR TKI used in first line and acquired T790M resistance, in combination

Table 1 Safety of Concurrent CPI and TKI therapy

\begin{tabular}{|c|c|c|c|c|c|c|c|}
\hline References & Phase & Setting & Oncogenic driver & No. patients & Arms/Treatment & Safety & Status \\
\hline \multirow[t]{2}{*}{ TATTON, [29] } & \multirow[t]{2}{*}{$\mathrm{Ib}$} & \multirow[t]{2}{*}{ 1st line +} & \multirow[t]{2}{*}{ EGFR } & $\begin{array}{l}34 \\
\text { Part A } 23\end{array}$ & $\begin{array}{l}\text { Part A: } 80 \mathrm{mg} \text { osi- } \\
\text { mertinib od + dur- } \\
\text { valumab } 3 \mathrm{mg} / \mathrm{kg} \\
\text { or } 10 \mathrm{mg} / \mathrm{kg} \mathrm{IV} \\
\text { q2w }\end{array}$ & \multirow[t]{2}{*}{ ILD $^{\text {a } 38 \% ~(13 / 34) ~}$} & \multirow[t]{2}{*}{ Terminated early } \\
\hline & & & & Part B 11 & $\begin{array}{l}\text { Part B: } 80 \mathrm{mg} \text { osi- } \\
\text { mertinib od + dur- } \\
\text { valumab } 10 \mathrm{mg} / \mathrm{kg} \\
\text { IV q2w }\end{array}$ & & \\
\hline $\begin{array}{l}\text { Group E checkmate } \\
370,[30]\end{array}$ & $\mathrm{I} / \mathrm{II}$ & 1st line & ALK & 13 & $\begin{array}{l}\text { Nivolumab } 240 \mathrm{mg} \\
\text { q2w + crizotinib } \\
250 \mathrm{mg} \text { bd }\end{array}$ & $\begin{array}{l}\text { Hepatic toxicity } 38 \% \\
(5 / 13)\end{array}$ & Terminated early \\
\hline \multirow[t]{2}{*}{ Felip E et al. [31] } & \multirow[t]{2}{*}{$\mathrm{Ib}$} & \multirow[t]{2}{*}{ 1st line +} & \multirow[t]{2}{*}{ ALK } & $\begin{array}{l}36 \\
\text { Group } 114\end{array}$ & $\begin{array}{l}\text { Group 1: Nivolumab } \\
3 \mathrm{mg} / \mathrm{kg} \\
\text { q2w + ceritinib } \\
450 \mathrm{mg} \text { od }\end{array}$ & \multirow[t]{2}{*}{$\begin{array}{l}\text { All grade diarrhoea } \\
69 \%(25 / 36), \text { all } \\
\text { grade rash } 64 \% \\
(23 / 36)\end{array}$} & \multirow[t]{2}{*}{ Amended } \\
\hline & & & & Group 222 & $\begin{array}{l}\text { Group 2: Nivolumab } \\
3 \mathrm{mg} / \mathrm{kg} \\
\text { q2w + ceritinib } \\
300 \mathrm{mg} \text { od }\end{array}$ & & \\
\hline Ma B et al. [32] & $\mathrm{Ib}$ & 1st line & EGFR & 28 & $\begin{array}{l}\text { Erlotinib } 150 \mathrm{mg} \text { PO } \\
\text { od + Atezolizumab } \\
1200 \mathrm{mg} \mathrm{q} 3 \mathrm{w}\end{array}$ & AE 39\% (11/28) & Completed \\
\hline \multirow[t]{2}{*}{$\begin{array}{l}\text { Gibbons DL et al. } \\
\text { [33] }\end{array}$} & \multirow[t]{2}{*}{ I } & \multirow[t]{2}{*}{ 1st line } & \multirow[t]{2}{*}{ EGFR } & $\begin{array}{l}20 \\
\text { Arm } 110\end{array}$ & $\begin{array}{l}\text { Arm } 1 \text { Dur- } \\
\text { valumab } 10 \mathrm{mg} / \\
\text { kg q2w + gefitinib } \\
250 \mathrm{mg} \text { od }\end{array}$ & \multirow[t]{2}{*}{ AE $20 \%(4 / 20)$} & \multirow[t]{2}{*}{ Completed } \\
\hline & & & & Arm 210 & $\begin{array}{l}\text { Arm 2: } 4 \text { weeks of } \\
\text { priming Gefi- } \\
\text { tinib } 250 \mathrm{mg} \text { od } \\
\text { followed by Dur- } \\
\text { valumab } 10 \mathrm{mg} / \mathrm{kg} \\
\mathrm{q} 2 \mathrm{w}+\text { gefitinib }\end{array}$ & & \\
\hline Gettingher et al. [34] & I & 1st and 2nd line & EGFR & $\begin{array}{l}21 \\
\text { (1) Tx naive }\end{array}$ & $\begin{array}{l}\text { Nivolumab } 3 \mathrm{mg} / \\
\mathrm{kg} \mathrm{q} 2 \mathrm{w}+\text { erlotinib } \\
150 \mathrm{mg} \text { od }\end{array}$ & $\mathrm{AE} 24 \%(5 / 21)$ & Completed \\
\hline $\begin{array}{l}\text { JAVELIN Lung 101, } \\
\text { [35] }\end{array}$ & $\mathrm{Ib}$ & 2nd line + & ALK & 28 & $\begin{array}{l}\text { Avelumab } 10 \mathrm{mg} / \mathrm{kg} \\
\text { q2w + Lorlatinib } \\
100 \mathrm{mg} \text { od }\end{array}$ & AE $53.6 \%(15 / 28)$ & Completed \\
\hline Kim DW et al. [36] & $\mathrm{Ib}$ & 1st Line & ALK & 21 & $\begin{array}{l}\text { Alectinib } 600 \mathrm{mg} \\
\text { bd + atezolizumab } \\
1200 \mathrm{mg} \mathrm{q} 3 \mathrm{w}\end{array}$ & AE $52.4 \%$ & Completed \\
\hline
\end{tabular}

${ }^{\mathrm{a}} I L D$ interstitial lung disease 
with durvalumab, a monoclonal antibody against PD-L1. The trial included two arms: (i) a dose escalation/expansion in EGFR-TKI pre-treated patients, and (ii) osimertinib/durvalumab in EGFR-TKI treatment naïve patients. Interstitial lung disease (ILD) was identified in 38\% (13/34) of patients across treatment arms, 26\% (6/23) in pre-treated patients and $64 \%(7 / 11)$ in treatment naïve patients. Five cases were reported as grade 3 or 4 , most managed with steroids. Of 21 evaluable patients in the pre-treated cohort, $57 \%(12 / 21)$ had a partial response (PR) and 43\% (9/21) stable disease (SD). Of 10 evaluable patients from the treatment-naïve arm, $80 \%(8 / 10)$ had PR and two had SD. Despite these efficacy results, investigators concluded that the primary end point of safety was not met and enrolment into the osimertinib and durvalumab treatment arm was terminated early. Enrolment into the expansion cohorts of MEK and MET inhibitor combinations demonstrated feasibility of combining osimertinib $80 \mathrm{mg}$ with selumetinib or savolitinib. Similarly, a phase $1 / 2$ study of crizotinib and nivolumab in ALK positive NSCLC was terminated prematurely due to safety concerns [30]. Five of the first 13 patients (38\%) developed $\geq$ grade 3 hepatic dysfunction, of which 2 patients died, 38\% (5/13) had a PR. The combination of nivolumab and ceritinib has been investigated by Felip and colleagues in a recent phase Ib multicentre study [31]. Dose limiting toxicities were identified in $17 \%$ of patients (6/36); most frequently reported grade $3 / 4$ adverse events (AEs) were increased ALT (25\%), increased GGT (22\%) and rash (11\%). Adverse events requiring dose change were reported in 33\% (12/36) of patients and dose interruptions in $81 \%$ patients $(29 / 36)$. Due to toxicity concerns, the trial was amended to allow alternative dosing strategy involving a run-in period of ceritinib followed by combination with nivolumab. Authors reported an overall response rate (ORR) of $68.8 \%$ and exploratory analysis indicated that PD-L1-positive disease was more likely to respond than PD-L1 negative, with overlapping confidence intervals.

In contrast to the safety concerns discussed above, other early phase clinical trials of concurrent CPI/TKI have shown acceptable safety profiles. Ma and colleagues evaluated the combination of erlotinib plus atezolizumab in EGFR-mutant disease [32]. Grade 3 or 4 AEs occurred in 39\% (11/28) of patients, with pyrexia and increased ALT representing the most common AEs. No dose limiting toxicities were identified, a response rate (RR) of $75 \%$ and median PFS of 11.3 months was demonstrated in the expansion stage $(n=20)$. Another study evaluated durvalumab in combination with gefitinib in EGFR-mutant NSCLC, concluding that treatment was generally tolerable given a treatment discontinuation rate of $20 \%$ due to grade $3 / 4$ toxicity (4/20 patients: increased ALT and/or AST in three, and pneumonitis in one). RR in 19 evaluable pts at 8 weeks was $78-80 \%$ [33]. Nivolumab and erlotinib was analysed by Gettingher and colleagues in first- and second-line therapy: grade 3 toxicity (increased liver enzymes two patients, diarrhoea two patients, weight loss one patient) occurred in 24\% (5/21) of patients, with no grade $4 / 5$ adverse events. In the TKItreated group, RR was $15 \%$ and 24-week PFS was $48 \%$. Authors concluded that this combination therapy was tolerable with durable response [34].

JAVELIN 101, a phase Ib study of concurrent avelumab and lorlatinib in ALK-positive patients, also demonstrated a reassuring safety profile, with no dose limiting toxicities [35]. Pre-treated patients received lorlatinib and avelumab. Despite a relatively high frequency of grade 3 and above toxicity, $53.6 \%$ (15/28), the side effect profile was manageable. The most commonly reported toxicities included hypertriglyceridemia $(14.3 \%, n=4)$ and GGT increase $(10.7 \%$, $n=3$ ). A RR of $46.4 \%$ was demonstrated and results from the phase II study in treatment naïve patients are awaited. Kim and colleagues evaluated the combination of alectinib plus atezolizumab in ALK positive, treatment naïve patients; treatment related grade 3 adverse events were reported in $52.4 \%$ of patients. There were no dose limiting toxicities observed. At median follow up of 13 months, ORR was $81 \%$ (95\% CI 58.1-94.6). Authors conclude that early efficacy results are encouraging and combination CPI plus TKI appears to be tolerable; however, as toxicities weren't specified, one can only assume they were easy to manage [36].

In summary, although some promising efficacy was seen using concurrent CPI/TKI combinations, significant CPIassociated morbidity and mortality was a striking concern in many cases, leading to the early discontinuation of some studies. Ongoing studies include (NCT02323126) evaluating efficacy and safety of nivolumab in combination with EGF816, a third generation TKI, and nivolumab in combination with INC280 in those previously treated with EGF816. Results are awaited from the phase I/Ib study (NCT02039674), evaluating pembrolizumab in combination with afatinib after progression on erlotinib and the phase $\mathrm{Ib}$ study (NCT02013219), evaluating atezolizumab in combination with erlotinib or alectinib. Although it is very early to judge, no clear patterns have emerged from trials as yet to highlight specific drugs or targets of concern that may be vulnerable to these problems.

\section{Sequential CPIs and TKIs}

As patients progress through treatment, a proportion will receive CPIs followed by TKIs. With durvalumab use as an adjuvant therapy following concurrent chemoradiotherapy (CCRT) in stage III NSCLC (PACIFIC trial), hazard ration (HR) for PFS for the whole study population was 0.55 (95\% CI 0.45-0.68) in favour of durvalumab whereas, for EGFR-mutation positive patients, HR was not significant at 0.76 (95\% CI $0.35-1.64)$ [23]. As molecular profiling is 
not performed routinely in all stage III NSCLC undergoing CCRT, there is, therefore, the potential for unidentified EGFR positive or ALK rearranged NSCLC patients to (i) receive limited benefit from the PACIFIC regimen, and (ii) be vulnerable to considerable toxicity if an actionable mutation is found at progression and sequential TKI therapy is employed. The reason for this latter concern is that, as well as side-effects with concurrent CPI/TKI combinations, recent retrospective reviews have highlighted a risk of serious toxicity when TKIs are prescribed sequentially following CPI use in stage III or stage IV disease.

Lisberg and colleagues evaluated pembrolizumab in a phase II clinical trial of EGFR-mutant TKI-naïve advanced NSCLC [37]. Recruitment was ceased due to lack of efficacy observed in 11 patients enrolled, with 1 patient demonstrating response later found to be EGFR wild type. Two deaths subsequently occurred within 6 months of enrolment, with one secondary to pneumonitis whilst on subsequent TKI. Of nine patients who received subsequent therapy, seven received erlotinib with a short median on-treatment duration of 109 days. AEs were secondary to TKI therapy in $86 \%$ (6/7) patients, with one case of grade 3 transaminitis and one grade 5 pneumonitis. The trial was not sufficiently powered to assess effects of prior pembrolizumab on subsequent EGFR TKI, although the results offered cause for concern regarding sequential use of CPI and TKI. Consistent with the above, Lin and colleagues have identified 11 patients with ALK fusion, ROS1 fusion or MET alteration that were treated in a single institution with CPI followed by crizotinib [38]. Hepatotoxicity with sequential CPI and TKI was significantly higher than that seen with TKI alone, including grade 3 or 4 increased ALT in $45.5 \%(5 / 11)$ vs. $8.1 \%$ (34/442 [95\% CI 5.4-10.5, $p<0.0001]$ ), and grade 3 or 4 increased AST in $36.4 \%$ (4/11) vs. 3.4\% (14/442 [95\% CI $1.9-5.5, p<0.0001])$. No grade 5 events occurred and all hepatotoxicity was reversible.

Another retrospective series analysed checkpoint inhibition followed by osimertinib [39]. In this study, severe CPIrelated AEs were identified in 15\% (6/41) of patients on osimertinib, with toxicity most common in those who had a shorter interval between CPI and TKI $(<3$ months since CPI: 5 of 21 patients, $24 \%$; $>3-12$ months since CPI: 1 of 8 patients, $13 \%$ ). AEs occurred at a median onset of 20 days after osimertinib (range 14-167 days), with all patients requiring steroids and most needing hospitalization. No toxicity was identified in those treated with sequential osimertinib followed by CPI $(n=29)$ or those treated with CPI followed by other EGFR-TKIs, afatinib or erlotinib, $(n=27)$.

In another observational study, sequential and combination nivolumab and EGFR-TKI therapy was evaluated [40]. 25.7\% (18/70 [95\% CI 16.0-37.6]) developed ILD. Stratification of patients by treatment with nivolumab revealed a strikingly high odds ratio of EGFR-TKI-associated ILD (5.09,
95\% CI 2.87-9.03) compared to those who did not receive nivolumab 1.22 (95\% CI 1.00-1.47); however, authors did not specify which EGFR-TKI was used in those who developed ILD. No other toxicities were evaluated. Amongst the 18 patients who developed ILD, the order of administration was identified in 15 patients all with nivolumab followed by TKI. The latency period from discontinuation of drug to development of ILD ranged from 19 to 147 days. Authors did not specify which EGFR-TKI was used with nivolumab but concluded that risk of EGFR-TKI ILD is increased with use of both CPI and TKI therapy. In contrast to previous toxicities described, early phase clinical trials have evaluated RET TKI BLU 667(NCT03037385) [41], poziotinib (NCT03066206) and TAK-788 (NCT02716116) in EGFR exon 20 ins mutation $[42,43]$. Results have demonstrated efficacy without increased toxicity despite some patients having previous TKI and CPI. Ongoing trials are evaluating these biomarkers and targeted therapies. The mechanisms to explain synergistic toxicity of some sequential CPI and TKI therapy is poorly understood, yet allowing for limitations from the above retrospective series it may be that toxicity is drug rather than class specific with crizotinib and osimertinib causing toxicity as discussed.

The main sequence of sequential therapy evaluated has been immunotherapy followed by TKI. However, the ATLANTIC study did assess durvalumab after TKI in EGFR or ALK positive NSCLC, in the third line setting with an acceptable safety profile [44]. Of note, the cohort of patients $(n=77)$ with a sensitising EGFR mutation in IMpower-150 previously treated with TKI therapy did not appear to demonstrate increased toxicity. No grade 5 immune-related AEs occurred in the EGFR positive population [27]. Studies described in Tables 1,2 have similarly failed to identified increased toxicity with prior TKI use suggesting that as the half-life of TKIs is shorter than immunotherapy this confers a potential lower risk of toxicity [29, 31, 34, 35, 39].

\section{Discussion and conclusions}

Here we have detailed past and present studies which highlight an emerging concern regarding serious toxicity of CPIs in combination with TKIs, whether prescribed concurrently or sequentially for stage IV NSCLC. As yet it is very early to state if there are clear patterns across these studies which may implicate certain drugs, targets or dosing schedules. Time from previous CPI appears to be a factor that can influence sequential TKI toxicity, perhaps reflecting the long half-life of CPIs and a context where we sometimes observe late immune-related toxicities months beyond treatment completion. Given the questionable efficacy of CPIs in never smoking subsets typically treated with TKIs, these challenges offer further reasons to be cautious in development of immunotherapy for this population. While 
Table 2 Safety of sequential CPI/TKI and TKI/CPI therapy

\begin{tabular}{|c|c|c|c|c|c|c|}
\hline References & Phase & Oncogenic driver & No. patients & Arms/Treatment & Safety & Status \\
\hline Lin et al. [38] & Retrospective & $\begin{array}{l}\text { ALK (3), ROS-1 } \\
\text { (3), MET (5) }\end{array}$ & 11 & $\begin{array}{l}\text { Pembrolizumab followed by } \\
\text { crizotinib ( } 6) \\
\text { Nivolumab followed by crizo- } \\
\text { tinib ( } 3) \\
\text { Atezolizumab followed by } \\
\text { crizotinib (1) } \\
\text { Nivolumab + ipilimumab fol- } \\
\text { lowed by crizotinib (1) }\end{array}$ & $\begin{array}{l}\text { G3/4 increase ALT } 45.5 \% \\
\text { (5/11) } \\
\text { G3/4 increase AST } 36.4 \% \\
\text { (4/11) }\end{array}$ & NA \\
\hline Schoenfeld et al. [39] & Retrospective & EGFR & 41 & $\begin{array}{l}\text { Nivolumab followed by osi- } \\
\text { mertinib ( } 24) \\
\text { Pembrolizumab followed by } \\
\text { osimertinib ( } 9 \text { ) } \\
\text { Atezolizumab followed by } \\
\text { osimertinib ( } 8 \text { ) }\end{array}$ & $\begin{array}{l}\text { AE } 15 \%(6 / 41) \\
\text { G3 pneumonitis }(n=4), \mathrm{G} 3 \\
\text { colitis }(n=1), \mathrm{G} 4 \text { hepatitis } \\
(n=1)\end{array}$ & NA \\
\hline Oshima et al. [40] & Retrospective & EGFR & 70 & Nivolumab followed TKI & ILD $25.7 \%(18 / 70)$ & NA \\
\hline Garassino et al. [44] & II & EGFR & 111 & $\begin{array}{l}\text { TKIs followed by Dur- } \\
\text { valumab }\end{array}$ & $\begin{array}{c}\mathrm{G} 3 / 4 \text { AE } 5 \%(6 / 111), \mathrm{G} 3 \\
\text { pneumonitis }(n=1)\end{array}$ & Ongoing \\
\hline
\end{tabular}

most practice-changing NSCLC CPI studies have tended to exclude EGFR and ALK positive patients, a subgroup analysis of the IMpower- 150 trial stands alone in describing benefit for EGFR-mutant patients to a CPI-based regimen [27].

The mechanism of toxicity with combination or sequential CPI and TKI therapy is poorly understood. CPIs release $\mathrm{T}$ cells from malignant immune suppression which could lead to generalised off-target immune system activation. It is proposed that TKIs may lead to release of tumour associated antigens via tumour cell death, increasing both basal and IFN gamma induced major histocompatibility complex (MHC) class-I presentation which in turn react with T cells causing heightened toxicity. TKIs may, therefore, harbour underappreciated immunomodulatory effects. More research is needed to establish what is truly going on $[45,46]$.

As more therapeutic targets are being discovered, it is becoming increasingly important for clinicians to correctly sequence CPIs and TKIs for delivery of safe and effective treatment. The results described above suggest that comprehensive molecular profiling of key NSCLC drivers, including in stage III disease, will help to inform optimal treatment sequencing and minimise potential toxicity. Future scrutiny will also involve CPI combination with TKI in never smoking molecular subsets beyond EGFR and ALK positive cancers, including those with BRAF V600, RET fusion and MET exon 14 who have shown promising TKI efficacy [47-49].

Open Access This article is licensed under a Creative Commons Attribution 4.0 International License, which permits use, sharing, adaptation, distribution and reproduction in any medium or format, as long as you give appropriate credit to the original author(s) and the source, provide a link to the Creative Commons licence, and indicate if changes were made. The images or other third party material in this article are included in the article's Creative Commons licence, unless indicated otherwise in a credit line to the material. If material is not included in the article's Creative Commons licence and your intended use is not permitted by statutory regulation or exceeds the permitted use, you will need to obtain permission directly from the copyright holder. To view a copy of this licence, visit http://creativecommons.org/licenses/by/4.0/.

\section{References}

1. Hanna N, Johnson D, Temin S, Masters G (2017) Systemic therapy for stage IV non-small-cell lung cancer: American Society of clinical oncology clinical practice guideline update summary. J Oncol Pract 13:832-837

2. Kalemkerian GP, Narula N, Kennedy EB, Biermann WA, Donnigton J, Leighl NB et al (2018) Molecular testing guideline for the selection of patients with lung cancer for treatment with targeted tyrosine kinase inhibitors: American Society of Clinical Oncology Endorsement of the College of American Pathologists/International Association for the Study of Lung Cancer/Association for Molecular Pathology Clinical Practice Guideline Update. J Clin Oncol 36:911-919

3. Solassol I, Pinguet F, Quantin X (2019) FDA- and EMA-approved tyrosine kinase inhibitors in advanced EGFR-mutated non-small cell lung cancer: safety, tolerability, plasma concentration monitoring, and management. Biomolecules. 9(11):668. https://doi. org/10.3390/biom9110668

4. European Medicines Association. Alecensa An overview of Alecensa and why it is authorised in the EU. https://www.ema.europ a.eu/en/medicines/human/EPAR/alecensa Accessed 05 Oct 2019

5. European Medicines Association. EPAR Summary for public Xalkori crizotinib. Available from: https://www.ema.europa.eu/ en/documents/overview/xalkori-epar-summary-public_en.pdf Accessed 05 Oct 2019

6. European Medicines Association. Zykadia ceritinib. https://www. ema.europa.eu/en/medicines/human/EPAR/zykadia Accessed 17 July 2020

7. European Medicines Association. Alunbrig Brigatinib. https ://www.ema.europa.eu/en/medicines/human/EPAR/alunbrig Accessed 17 July 2020 
8. European Medicines Association. Lorviqua. https://www.ema. europa.eu/en/medicines/human/EPAR/lorviqua Accessed 17 July 2020

9. FDA US Food \& Drug Administration. Alectinib approved for (ALK) positive metastatic non-small cell lung cancer (NSCLC). https://www.fda.gov/drugs/resources-information-approved-drugs /alectinib-approved-alk-positive-metastatic-non-small-cell-lungcancer-nsclc Accessed 05 Oct 2019)

10. FDA US Food \& Drug Administration. FDA Approves Crizotinib Capsules. https://www.fda.gov/drugs/resources-informatio n-approved-drugs/fda-approves-crizotinib-capsules Accessed 05 Oct 2019)

11. FDA US Food \& Drug Administration. FDA broadens ceritinib indication to previously untreated ALK-positive metastatic NSCLC. https://www.fda.gov/drugs/resources-informatio $\mathrm{n}$-approved-drugs/fda-broadens-ceritinib-indication-previously -untreated-alk-positive-metastatic-nsclc Accessed 17 July 2020

12. FDA US Food \& Drug Administration. Brigatinib. https://www. fda.gov/drugs/resources-information-approved-drugs/brigatinib Accessed 17 July 2020

13. FDA US Food \& Drug Administration. FDA approves lorlatinib for second- or third-line treatment of ALK-positive metastatic NSCLC. https://www.fda.gov/drugs/fda-approves-lorlatinib -second-or-third-line-treatment-alk-positive-metastatic-nsclc Accessed 17 July 2020

14. European Medicines Association. Summary of opinion post authorisation. https://www.ema.europa.eu/en/documents/ smop/chmp-post-authorisation-summary-positive-opinion-tafin lar_en.pdf Accessed 17 July 2020

15. FDA US Food \& Drug Administration. FDA grants regular approval to dabrafenib and trametinib combination for metastatic NSCLC with BRAF V600E mutation. https://www.fda. gov/drugs/resources-information-approved-drugs/fda-grant s-regular-approval-dabrafenib-and-trametinib-combinatio n-metastatic-nsclc-braf-v600e Accessed 17 July 2020

16. FDA US Food \& Drug Administration. FDA Approves first therapy for patients with lung and thyroid cancers with a certain genetic mutation or fusion. https://www.fda.gov/news-event s/press-announcements/fda-approves-first-therapy-patientslung-and-thyroid-cancers-certain-genetic-mutation-or-fusion Accessed 17 July 2020)

17. FDA US Food \& Drug Administration. FDA approves entrectinib for NTRK solid tumors and ROS-1 NSCLC. https://www. fda.gov/drugs/resources-information-approved-drugs/fda-appro ves-entrectinib-ntrk-solid-tumors-and-ros-1-nsclc Accessed 17 July 2020

18. Reck M, Rodríguez-Abreu D, Robinson AG, Hui R, Csőszi T, Fülöp A et al (2016) Pembrolizumab versus Chemotherapy for PD-L1-Positive Non-Small-Cell lung cancer. N Engl J Med 375:1823-1833

19. Rittmeyer A, Barlesi F, Waterkamp D (2017) Atezolizumab versus docetaxel in patients with previously treated non-small-cell lung cancer (OAK): a phase 3, open-label, multicentre randomised controlled trial. Lancet 389:255-265

20. Herbst RS, Baas P, Kim D-W, Felip E, Perez-Gracia JL, Han J-Y et al (2016) Pembrolizumab versus docetaxel for previously treated, PD-L1-positive, advanced non-small-cell lung cancer (KEYNOTE-010): a randomised controlled trial. Lancet 387:1540-1550

21. Brahmer J, Reckamp KL, Bass P, Crino L, Eberhardt WEE, Poddubskaya E et al (2015) Nivolumab versus docetaxel in advanced squamous-cell non-small-cell lung cancer. N Engl J Med 373:123-135

22. Borghaei H, Paz-Ares L, Horn L, Spiegel DR, Steins M, Reday ME et al (2015) Nivolumab versus docetaxel in advanced nonsquamous non-small-cell lung cancer. N Engl J Med 373:1627-1639

23. Antonia SJ, Villegas A, Daniel D, Vicente D, Murakami S, Hui $R$ et al (2017) Durvalumab after chemoradiotherapy in stage III non-small-cell lung cancer. N Engl J Med 377:1919-1929

24. Gandhi L, Rodríguez-Abreu D, Gadgeel S, Esteban E, Felip E, De Angelis F et al (2018) Pembrolizumab plus chemotherapy in metastatic non-small-cell lung cancer. N Engl J Med 378:2078-2092

25. Paz-Ares L, Luft A, Vicente D, Tafreshi A, Gümüş M, Mazières $\mathrm{J}$ et al (2018) Pembrolizumab plus chemotherapy for squamous non-small-cell lung cancer. N Engl J Med 379:2040-2051

26. West H, McCleod M, Hussein M, Morabito A, Rittmeyer A, Conter HJ et al (2019) Atezolizumab in combination with carboplatin plus nab-paclitaxel chemotherapy compared with chemotherapy alone as first-line treatment for metastatic nonsquamous non-small-cell lung cancer (IMpower130): a multicentre, randomised, open-label, phase 3 trial. Lancet Oncol 20:924-937

27. Reck M, Mok TSK, Nishio M, Jotte RM, Cappuzzo F, Orlandi F et al (2019) Atezolizumab plus bevacizumab and chemotherapy in non-small-cell lung cancer (IMpower150): key subgroup analyses of patients with EGFR mutations or baseline liver metastases in a randomised, open-label phase 3 trial. Lancet Respir Med 7:387-401

28. European Medicines Agency. Tecentriq (atezolizumab) An overview of Tecentriq and why it is authorised in the EU. https ://www.ema.europa.eu/en/documents/overview/tecentriq-eparmedicine-overview en.pdf Accessed 22 July 2020)

29. Oxnard GR, Yang C-H, Yu H, Kim S-W, Saka H, Horn L et al (2020) TATTON: a multi-arm, phase $1 \mathrm{~b}$ trial of osimertinib combined with selumetinib, savolitinib, or durvalumab in EGFR-mutant lung cancer. Ann Oncol 31(4):507-516

30. Spigel DR, Reynolds C, Waterhouse D, Garon EB, Chandler J, Babu S et al (2018) Phase 1/2 Study of the Safety and Tolerability of Nivolumab Plus Crizotinib for the first-line treatment of anaplastic lymphoma kinase translocation-positive advanced non-small cell lung cancer (CheckMate 370). J Thoracic Oncol 13(5):682-688

31. Felip E, de Braud FG, Maur M, Loong HH, Shaw AT, Vansteenkiste JF et al (2020) Ceritinib plus nivolumab in patients with advanced ALK-rearranged non-small-cell lung cancer: results of an open-label, multicenter, phase 1B study. J Thorac Oncol 15(3):392-403

32. Ma BBY, Rudin CM, Cervantes A, Dowlati A, Costa D, Schmid $P$ et al (2016) 441O-Preliminary safety and clinical activity of erlotinib plus atezolizumab from a Phase Ib study in advanced NSCLC. Ann Oncol 27(suppl_9):ix139-ix156. https://doi. org/10.1093/annonc/mdw594

33. Gibbons DL, Chow LQ, Kim DW, Kim SW, Yeh T, Song X et al (2016) 57O Efficacy, safety and tolerability of MEDI4736 (durvalumab [D]), a human IgG1 anti-programmed cell deathligand-1 (PDL1) antibody, combined with gefitinib (G): a phase I expansion in TKI-naïve patients (pts) with EGFR mutant NSCLC. J Thorac Oncol. 11:S79

34. Gettingher S, Helmann MD, Chow LQM, Borghaei H, Antonia S, Brahmer JR et al (2018) Nivolumab plus Erlotinib in patients with EGFR-mutant advanced NSCLC. J Thoracic Oncol 13(9):1363-1372

35. Shaw AT, Lee S-H, Ramalingam SS, Bauer TM, Boyer MJ, Costa EC et al (2018) Avelumab (anti-PD-L1) in combination with crizotinib or lorlatinib in patients with previously treated advanced NSCLC: Phase 1b results from JAVELIN Lung 101. J Clin Oncol 36(15_suppl):9008

36. Kim DW, Gadgeel SM, Gettinger SN, Riley GJ, Oxnard GR, Mekhail T et al (2018) Safety and clinical activity results from a phase Ib study of alectinib plus atezolizumab in ALK + 
advanced NSCLC (aNSCLC). J Clin Oncol. 36(15):9009. https ://doi.org/10.1200/jco.2018.36.15_suppl.9009

37. Lisberg A, Cummings A, Goldman JW, Bornazyan K, Reese $\mathrm{N}$, Wang $\mathrm{T}$ et al (2018) A phase II study of pembrolizumab in egfr-mutant, PD-L1 +, tyrosine kinase inhibitor naïve patients with advanced NSCLC. J Thoracic Oncol 13(8):1138-1145

38. Lin JJ, Chin E, Yeap BY, Ferris LA, Kamesan V, Lennes IT et al (2019) Increased hepatotoxicity associated with sequential immune checkpoint inhibitor and Crizotinib therapy in patients with non-small cell lung cancer. J Thoracic Oncol 14(1):135-140

39. Schoenfeld AJ, Arbour KC, Rizvi H, Iqbal AN, Gadgeel SM, Girshman J et al (2019) Severe immune-related adverse events are common with sequential PD-(L)1 blockade and osimertinib. Ann Oncol 30(5):839-844

40. Oshima Y, Tanimoto T, Yuji K, Tojo A (2018) EGFR-TKI-Associated Interstitial Pneumonitis in Nivolumab-treated patients with non-small cell lung cancer. JAMA Oncol. 4(8):1112-1115

41. Subbiah V, Taylor M, Lin J. Highly potent and selective RET inhibitor, BLU-667, achieves proof of concept in a phase I study of advanced, RET-altered solid tumors. Cancer Research. Cancer Research 2018; 78(13Supplement): CT043-CT043, presented at AACR Annual Meeting 2018, 2018; Chicago, IL

42. Robichaux JP, Elamin YY, Tan Z, Carter BW, Zhang S, Liu S et al (2018) Mechanisms and clinical activity of an EGFR and HER2 exon 20-selective kinase inhibitor in non-small cell lung cancer. Nat Med 24:638-646

43. Doebele RC, Riely GJ, Spira AI, Horn L, Piotrowska Z, Costa DB et al (2018) First report of safety, PK, and preliminary antitumor activity of the oral EGFR/HER2 exon 20 inhibitor TAK-788 (AP32788) in non-small cell lung cancer (NSCLC). J. Clin Oncol. 36(15 (suppl)):9015
44. Garassino MC, Cho B-C, Kim J-H, Mazières J, Vansteenkiste J, Lena $\mathrm{H}$ et al (2018) Durvalumab as third-line or later treatment for advanced non-small-cell lung cancer (ATLANTIC): an openlabel, single-arm, phase 2 study. Lancet Oncol 19:521-536

45. Tang C, Jiang W, Yap TA (2018) Efficacy and toxic effects of cancer immunotherapy combinations-a double-edged sword. JAMA Oncol 4(8):1116-1117

46. Lizotte PH, Hong RL, Luster TA et al (2018) A high-throughput immune-oncology screen identifies EGFR inhibitors as potent enhancers of antigen-specific cytotoxic t-lymphocyte tumor cell killing. Cancer Immunol Res 12:1511-1523

47. Planchard D, Smit EF, Groen HJM, Mazires J, Besse B, Helland A et al (2017) Dabrafenib plus trametinib in patients with previously untreated BRAFV600E-mutant metastatic non-smallcell lung cancer: an open-label, phase 2 trial. Lancet Oncol 18(10):1307-1316

48. Gainor JF, Lee DH, Curigliano G, Doebele RC, Kim D-W, Baik CS et al 2019 Clinical activity and tolerability of BLU-667, a highly potent and selective RET inhibitor, in patients (pts) with advanced RET-fusion + non-small cell lung cancer (NSCLC). J Clin Oncol 37, (suppl; abstr 9008)

49. Awad MM, Leonardi GC, Kravets S Dahlberg SE, Drilon AE, Noonan 2017 Impact of MET inhibitors on survival among patients (pts) with MET exon 14 mutant (METdel14) non-small cell lung cancer (NSCLC). J Clin Oncol. 35 (suppl; abstract 8511)

Publisher's Note Springer Nature remains neutral with regard to jurisdictional claims in published maps and institutional affiliations. 